\title{
Soil organic carbon mapping and prediction based on depth intervals using kriging technique: A case of study in alluvial soil from Sudan
}

\author{
Magboul M. Sulieman a,b,*, Abdallah M. AlGarni c,d \\ a Department of Soil and Environment Sciences, Faculty of Agriculture, University of Khartoum, Khartoum, Sudan \\ ${ }^{b}$ Department of Soil Science, College of Food and Agriculture Sciences, King Saud University, Riyadh, Saudi Arabia \\ c Institute of Environmental Studies, University of Khartoum, Khartoum, Sudan \\ d Member of Saudi Society for Geosciences, College of Science, King Saud University, Riyadh, Saudi Arabia
}

\section{Article Info}

Received : 19.04 .2018

Accepted : 27.11.2018

\begin{abstract}
Soil organic carbon plays a vital role in the arid and semiarid regions. This study aimed to predict and map soil organic carbon content at soil depth intervals of 0-0.3 m, 0.3-0.6 m, 0.6-0.9 m, and 0.9-1.2 $\mathrm{m}$ in alluvium soils along Blue Nile and River Nile, Sudan. Ordinary kriging $(\mathrm{OK})$ technique was used as a geostatistical tool and applied to model the spatial variability of soil organic carbon in the study area. A total of 38 soil profiles were excavated in the study area and 152 samples from the four depths intervals were collected for determining organic carbon content. Results revealed that, the spatial autocorrelation for the different soil layers was moderate to weak with a nugget to sill ratios ranging from 0.21 to 0.86 suggesting their controlled by both intrinsic and extrinsic factors. The root mean square error standardized (RMSE) of the predictions ranging from 0.79 to 0.83 indicating that the model which generated by ordinary kriging was correctly estimating the variability of soil organic carbon in the study area.
\end{abstract}

Keywords: Alluvial soil, spatial autocorrelation, semivariogram, soil organic carbon, Cokriging, soil depth intervals.

(C) 2019 Federation of Eurasian Soil Science Societies. All rights reserved

\section{Introduction}

It is well known that soil is the major pool of organic carbon in the terrestrial biosphere, storing more carbon than that in the plants and atmosphere together (Scharlemann et al., 2014). Soil organic carbon (SOC) plays an important role in agricultural productivity (Acín-Carrera et al., 2013), therefore SOC could be a useful indicator for soil health and quality for soil fertility and climate regulation (Beguería et al., 2015; Chen et al., 2017).

Level of SOC mainly revert to soil properties such as aggregate stability, soil structure, porosity or nitrogen content (Cotching et al., 2014; Bienes et al., 2016, Sulieman et al., 2018) and resultant soil processes related to land degradation like soil erosion (García-Díaz et al., 2016; Jin et al., 2009). Thus, nature-based solutions should be applied in order to conserve the soil carbon stocks in some specific degraded environments such as forests, agricultural fields or alluvial areas (Keesstra et al., 2018, Sulieman et al., 2016).

In this way alluvial areas over the world are highly demanded for intensive agricultural production, and this is mostly attributed to their high quality of the soils and water as well (Parker, 1995; Bertalan et al., 2016). In the South-east Anatolia region of Turkey, Dengiz (2010) studied the morphology, physico-chemical properties and classified the soils developed on terraces of the Tigris River. He concluded that, the soils developed on floodplain were characterized by weak pedogenesis, however, development of the B horizon (Bw, Bt, Bss) and carbonate

\footnotetext{
${ }^{*}$ Corresponding author.

Department of Soil and Environment Sciences, Faculty of Agriculture, University of Khartoum, Khartoum North, 13314 Shambat, Sudan

Tel.: +966542995460

E-mail address: magboul@uofk.edu

e-ISSN: $2147-4249$
} 
accumulation were the main pedogenic processes in terraces soils, and the main soil order were Entisols, Inceptisols, Alfisols and Vertisols. Specifically, in North African regions, non-suitable land use managements are affecting the soil properties and microbial diversity and only well-planned decisions by farmers and policy makers could be revert this dramatically situation (Bounouara et al., 2017; Camilli et al., 2016, Mlih et al., 2016). More specifically, in Sudan, the most irrigated intensive crop farming areas for vegetables and fruits are largely situated within the alluvium plains of the Blue Nile, White Nile, and River Nile terraces. In these alluvial terraces, research on soil properties and their relationships among them that condition their geographical distribution is not highly conducted (Elfaki et al., 2015; Sulieman et al., 2015a,b, 2016).

The distribution of SOC and other soil properties change across the landscape and it also varies by depth (Bogunovic et al., 2017, Sulieman et al., 2018). Dengiz et al. (2015) studied the effects of soil types and land use - land cover on SOC density at Madendere watershed, they concluded that, the two factors had great influence on SOC density spatial variation at the different land use systems. In most natural soils, SOC is higher in the surface horizons and it decreases with depth, however, in agricultural areas the spatial variability can be very high (Lado et al., 2004). Such depth-wise variability is mostly continuous in forest or mountainous soils (Bishop et al., 1999; Hartemink and Minasny, 2014) except in soils with a strong human impact like some soils in the Netherlands (Kempen et al., 2011) or after the abandonment (Rodrigo-Comino et al., 2017). Therefore, soil human impacts can be considered as a driving factor of SOC changes (Gómez et al., 2009; Johannes et al., 2017). Despite the most SOC studies and inventories are confined to $30 \mathrm{~cm}$ soil depth, the amount of SOC stored below $30 \mathrm{~cm}$ is also relevant in many ecosystems (IPCC, 2003; Smith et al., 2005). Sudan is a poorly mapped country in terms of soil data (Sulieman et al., 2018). Likewise, the spatial variability of SOC is not yet understanding all over the country and, most specifically, in alluvial areas.

Geographic Information Systems can contribute as a useful tool for soil mapping (Pereira et al., 2018). The creation of soil maps that show the distribution of soil properties along the landscape is considered a powerful tool to organize the territory suitably (Behrens et al., 2010; Grunwald, 2009). To achieve this goal in semiarid environments, different methods have been applied such as modelling (Keshavarzi et al., 2018; Shiri et al., 2017), pedotranfers (Nasri et al., 2015) or geospatial analysis (Zeraatpisheh et al., 2017).

In this current study, it was pretend to fill lack of information by applying digital soil mapping techniques to quantify the SOC content and distribution. Therefore, the main objective of this research is to applied ordinary kriging $(\mathrm{OK})$ geostatistical method to predict and map the spatial distribution of SOC at soil depth intervals of 0-30 cm, 30-60 cm, 60-90 cm, and 90-120 cm in selected alluvium soils along the Blue Nile and River Nile terraces in Sudan.

\section{Material and Methods}

\section{Study Area}

The studied samples representing soils from across the upper, middle, and lower Nile River terraces and the upper and lower Blue Nile terraces (1000" to 15 $45^{\prime \prime} \mathrm{N}, 30^{\circ} 00^{\prime \prime}$ to $35^{\circ} 00^{\prime \prime}$ E) in Sudan were collected and analyzed (Figure 1). According to the updated map of climatic classification (Peel et al., 2007), the climate of the study area varies from arid to semiarid zone, characterized by hot dry in most periods of the year to relatively heavy rains during short period in summers. The mean annual temperature varies from 28.3 to 29.6 ${ }^{\circ} \mathrm{C}$ and mean annual precipitation varies from $163 \mathrm{~mm}$ to more than $700 \mathrm{~mm}$ (Van der Kevie, 1976).

Geologically, the alluvium soils along Nile River belong to the Cretaceous Period which comprises continental clastic sediments including sandstones, siltstones, mudstones and conglomerates and locally known as Nubian Sandstone Formation. Whereas, the soils from Blue Nile terraces belong to the Tertiary Period (Gezira Formation), which comprises unconsolidated fine materials and gravels, and Quaternary Periods comprises unconsolidated sands with some gravels, and shales locally known as Umm-Ruwaba Formation (Figure 2) (Whiteman, 1971; Ministry of Energy and Mines, 1981). Topographically, the study area is mostly gently undulating. The soil moisture and temperature regimes are aridic to ustic and thermic to hyperthermic, respectively, and the soils are classified as fluvents suborder according to USDA soil Taxonomy (Soil Survey Staff, 2014). The main form of land use in the study area is intensive irrigated agriculture for vegetables and fruits. Ecologically, the area lies within the desert to semi desert ecological zone (Harrison and Jackson, 1958), consists of a wide variety of natural plant species, notably Fagonia cretica, Indigofera oblongifolia, Aerva javonica, Acacia toritllis and Maerua crassifolia. 


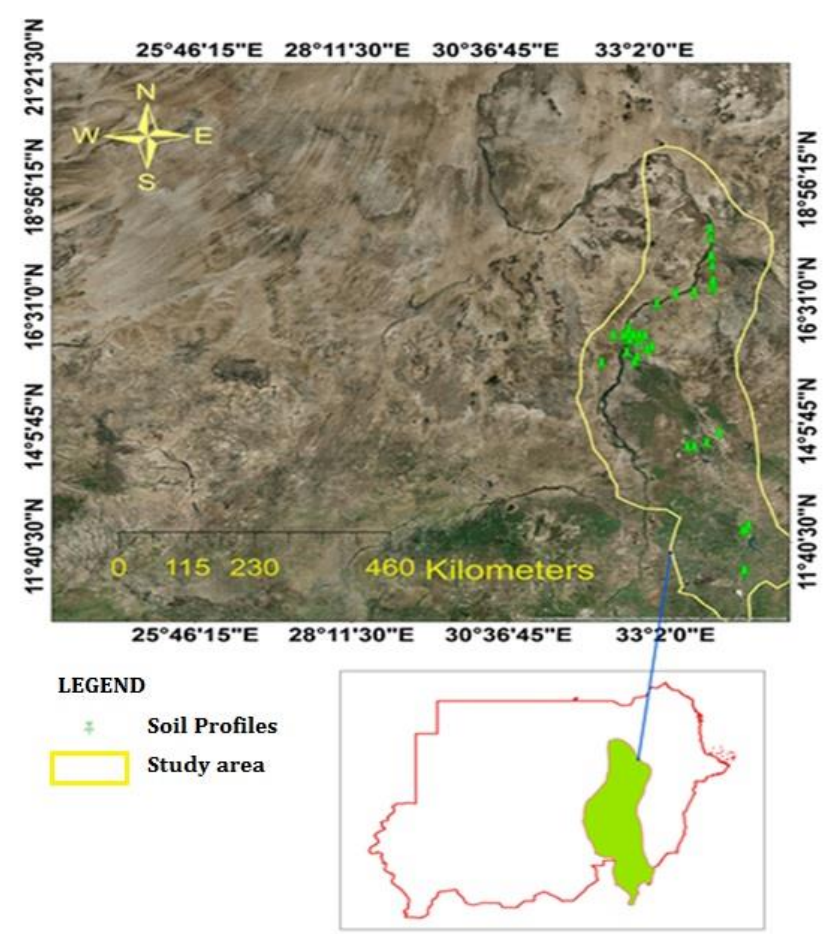

Figure 1. Study area represent some of selected profile's locations along the Nile River and Blue Nile terraces

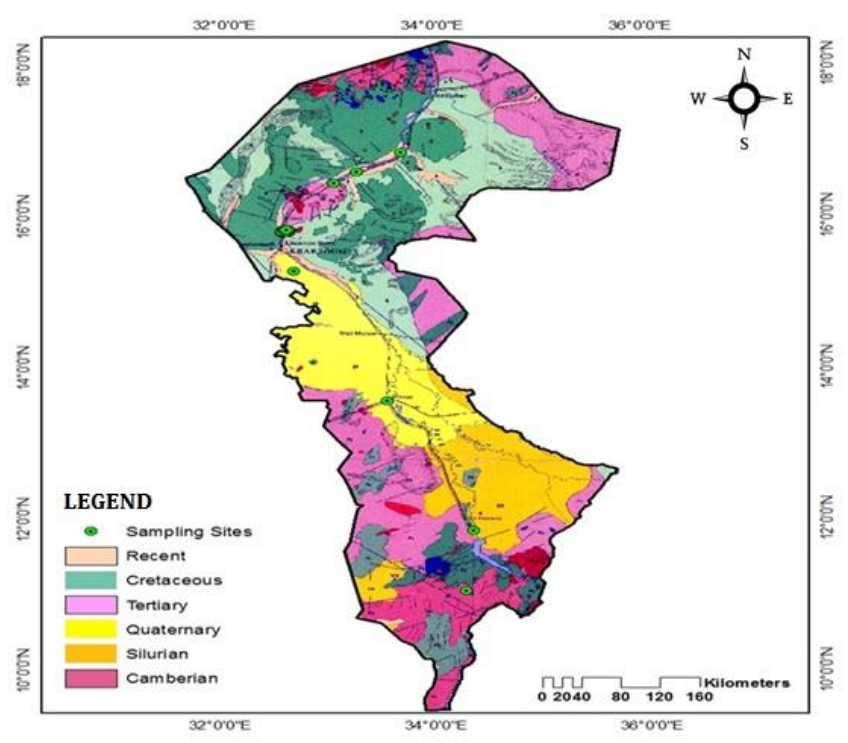

Figure 2. Selected profiles locations inside the subset of geological map of Sudan

\section{Soil sampling and analysis}

A total of 38 soil profiles were excavated along the study area, fully described following the field books of Schoeneberger (2012), classified according to USDA soil taxonomy (Soil Survey Staff, 2014). Based on the genetic horizons, a total of 152 soil samples were collected from four depth intervals of 0 to $120 \mathrm{~cm}$ within each profile as follows; 0-30 cm, 30-60 cm, 60-90 cm, and 90-120 cm. In laboratory, soil samples were first air-dried, ground, and then passed through a $2 \mathrm{~mm}$ sieve to obtain the fine fraction. The soil organic carbon was measured by wet oxidation with chromic acid and back titrated with ferrous ammonium sulfate following the standard Walkey and Black method (Nelson and Sommers, 1996). A histogram tool in Arc GIS software version 10.4 was used to identify the outliers of SOC, where a more isolated bar from the main group of bars in the histogram was taken to represent a possible outlier (Chabala et al., 2017). Therefore, in case if outliers observed, the laboratory analyses were repeated and any outliers recorded one more were removed from the samples set.

\section{Statistical analyses}

General basic statistics parameters such as minimum and maximum values, mean, median, standard deviations, first quartile, third quartile, Skewness, and Kurtosis were calculated for both tested and validated samples to provide a basic understanding of the characteristics of data using Statistix software version 8.1 (Steel and Torrie, 1980).

\section{Predicting spatial distribution of SOC}

In this study, the spatial variability of SOC at four depths intervals was studied using ordinary kriging (OK) method. OK is a geostatistical models that use a set of statistical tools to predict the value of a given soil property (in this case SOC) at a location that was not sampled (Goovaerts, 1998; Regalado and Ritter, 2006; Johnston et al., 2001). Based on OK, the predicted SOC at an unsampled location ( $\left.p r e d\left(x_{0}\right)\right)$, using measured values $o b s(x i)$ is given as:

$$
\operatorname{pred}\left(x_{0}\right)=\sum_{i=1}^{n} w_{i}\left(x_{0}\right) * \operatorname{obs}\left(x_{i}\right)
$$

Where $w_{i}\left(x_{0}\right)$ is the kriging weight.

In order to model the spatial variability of SOC with OK, further data evaluation was performed to check whether the SOC data conformed to the necessary assumptions required for OK include that data are required to be normally distributed with no trend. The histogram and normal quantile-quantile (Q Q) plots tools in 
ArcGIS were used to evaluate the distribution of the data. The trend analysis tool was also applied to check for trend in the SOC data set. The data check revealed that the data set had no trend. The central tool of geostatistical procedures such as $\mathrm{OK}$ is the semivariance, which is half the expected squared difference between the SOC values at two locations. The semivariance quantified the spatial variability of SOC for all possible pairing of SOC data. The plot of the semivariance as a function of distance is referred to as a semivariogram (Chahouki et al., 2011). The semivariogram described how SOC varied with distance among the sampling locations. Positive definite models were applied to fit the semivariogram using ordinary least squares to capture spatial features of the SOC. An automated fitting procedure was followed when fitting the semivariogram of SOC using the exponential model. All data processing and analysis for OK were done in ArcGIS software package version 10.4 with the variogram redrawn in Microsoft excel.

\section{Data validation}

The prediction accuracy of SOC at the unsampled locations was evaluated using the leave-out-one cross validation (LOCV) techniques (Reza et al., 2010; Liu et al., 2013; Martín et al., 2016). The indices used during LOCV were root mean square error (RMSE), average standard error (ASE), and standardized RMSE (RMSSE). Thus, for each of the sampled locations, there was a measured value for SOC (obs(xi)) and a predicted value (pred(xi)), with standard values being obs1(xi) and obs2(xi), respectively. The ASE, RMSE, and RMSSE were calculated according to Yang et al. (2009) as follows:

$$
\begin{gathered}
A S E=\sqrt{\frac{1}{n} \sum_{i=1}^{n}\left[\operatorname{pred}_{(x i)}-\left(\frac{\sum_{i=1}^{n} \operatorname{pred}_{(x i)}}{n}\right)\right]^{2}} \\
R M S E=\sqrt{\frac{1}{n} \sum_{i=1}^{n}\left[o b s_{(x i)}-\operatorname{pred}_{(x i)}\right]^{2}} \\
R M S S E=\sqrt{\frac{1}{n} \sum_{i=1}^{n}\left[o b s 1_{(x i)}-o b s 2_{(x i)}\right]^{2}}
\end{gathered}
$$

Where $n$ is the number of validation points.

The RMSSE varies between 0 and 1 , with a value of 1 indicating a perfect model and 0 indicating a poor model. In addition, a cross plot of measured and predicted SOC values was drawn in a scatter plot and associated summary statistics of predicted SOC values were compared with those of measured values (Leuangthong et al., 2004) using the Sample $t$-test (Paired $t$-test).

\section{Results and Discussion}

\section{Summary of basic statistics}

The summary of descriptive statistics for the measured and predicted SOC data are presented in Table 1. Results show that the SOC showed a decreasing trend with increasing soil depth. Mean SOC for both measured and predicted was $0.75,0.64$, and $0.50 \mathrm{~g} \mathrm{~kg}^{-1}$ for soil layers $0-30 \mathrm{~cm}, 30-60 \mathrm{~cm}$, and $90-120 \mathrm{~cm}$, respectively, while the mean for measured and predicted SOC at layer $60-90 \mathrm{~cm}$ was 0.56 and $0.59 \mathrm{~g} \mathrm{~kg}^{-1}$, respectively. This indicates that the model was reliable for SOC prediction in this depth compared to the other three depths, meanwhile, it can be taken into account. The standard deviation ( \pm SD) in the measured SOC was $0.53,0.52$, 0.46 , and $0.43 \mathrm{~g} \mathrm{~kg}^{-1}$ for layers $0-30 \mathrm{~cm}, 30-60 \mathrm{~cm}, 60-90 \mathrm{~cm}$, and $90-120 \mathrm{~cm}$, respectively compared to 0.29 , $0.29,0.28$, and $0.26 \mathrm{~g} \mathrm{~kg}^{-1}$, respectively for the same layers in the predicted SOC. The coefficients of variation (CV) of SOC for both measured data for all layers ranged from 71.56 to $86.72 \%$ with gradually increased from the surface to the bottom layers in the soil profile. This could be due to the complex textural layers. This result is in line with previous studies of He et al. (2009) and Chen et al. (2015). A coefficient of variation (CV) value of $10 \%$ indicates low variability and values ranging from $10-90 \%$ indicate a moderate variability; CV values > $90 \%$ indicate high variability (Fang et al., 2012). Therefore, measured SOC in our study indicated a moderate variability. The coefficients of skewness at four depths were $0.53,0.61,71$, and 1.23 in the measured SOC, respectively and 0.49 and $0.20,0.23$, and 0.53 in the predicted SOC, respectively. This indicated that the measured and predicted SOC followed similar pattern distribution. Further, the skewness $(<0.5)$ and kurtosis 
$(<3)$ of SOC indicated the approximate normal distributions of data (Rosemary et al., 2017). The first and third quartiles at the four depths were $(0.51,0.91),(0.34,0.90),(0.40,0.78)$, and $(0.30,0.61) \mathrm{g} \mathrm{kg}-1$, respectively in the predicted values, which were comparable to the recorded values in the measured data. Overall, the summary statistics in the measured and predicted SOC indicated that the model was well fitted for the prediction of SOC at the different soil layers.

Table 1. Summary basic statistics of the measured and predicted SOC at four different layers.

\begin{tabular}{|c|c|c|c|c|c|c|c|c|c|c|c|}
\hline \multirow{2}{*}{$\begin{array}{l}\text { Depth } \\
\text { (cm) }\end{array}$} & \multirow{2}{*}{ SOC } & Mean & Minimum & Maximum & Median & \multirow[t]{2}{*}{$\pm \mathrm{SD}^{\mathrm{a}}$} & \multirow[t]{2}{*}{ CV (\%) } & \multirow[t]{2}{*}{$1^{\text {st }} \mathrm{Qu}$} & \multirow[t]{2}{*}{$3^{\text {rd }} \mathrm{Qu}$} & \multirow[t]{2}{*}{ Skewness } & \multirow[t]{2}{*}{ Kurtosis } \\
\hline & & \multicolumn{4}{|c|}{$\mathrm{g} \mathrm{kg}^{-1}$} & & & & & & \\
\hline \multirow[t]{2}{*}{$0-30$} & Measured & 0.75 & 0.10 & 1.84 & 0.59 & 0.53 & 71.56 & 0.24 & 1.28 & 0.53 & -0.93 \\
\hline & Predicted & 0.75 & 0.13 & 1.19 & 0.77 & 0.29 & 40.45 & 0.51 & 0.99 & -0.49 & -0.84 \\
\hline \multirow[t]{2}{*}{$30-60$} & Measured & 0.64 & 0.04 & 1.92 & 0.46 & 0.52 & 81.26 & 0.19 & 1.16 & 0.64 & -0.75 \\
\hline & Predicted & 0.64 & 0.13 & 1.16 & 0.66 & 0.29 & 45.97 & 0.34 & 0.90 & -0.20 & -1.13 \\
\hline \multirow[t]{2}{*}{$60-90$} & Measured & 0.56 & 0.04 & 1.76 & 0.53 & 0.46 & 79.86 & 0.16 & 0.96 & 0.71 & -0.51 \\
\hline & Predicted & 0.59 & 0.09 & 1.24 & 0.61 & 0.28 & 47.56 & 0.40 & 0.78 & 0.23 & -0.45 \\
\hline \multirow[t]{2}{*}{$90-120$} & Measured & 0.50 & 0.04 & 1.68 & 0.44 & 0.43 & 86.72 & 0.13 & 0.67 & 1.23 & 1.06 \\
\hline & Predicted & 0.50 & 0.08 & 1.08 & 0.49 & 0.26 & 53.61 & 0.30 & 0.61 & 0.58 & -0.41 \\
\hline
\end{tabular}

$\pm \mathrm{SD}=$ standard deviation; $\mathrm{CV}=$ coefficient of variance; $1^{\text {st }} \mathrm{Qu}=25 \% ; 3^{\text {rd }} \mathrm{Qu}=75 \%$.

\section{Variography and kriging interpolated of SOC at different depth intervals}

Figures 3 shows the fitted semivariogram and the associated variograhpic parameters for the different depth intervals. Depending on the criteria suggested by Cambardella et al. (1994), the spatial dependence or autocorrelation was judged to be strong if the nugget to sill ratio was less than 0.25 , to be moderate if between 0.25 and 0.75 , and to be weak if higher than 0.75. In this study, the spatial autocorrelation (SAC) at depth intervals of $0-30 \mathrm{~cm}, 30-60 \mathrm{~cm}$, and $60-90 \mathrm{~cm}$ has a nugget to sill ratios of $0.42,0.28,21$ respectively, and at layer $90-120 \mathrm{~cm}$ was 0.86 (Fig. 3a,b,c,d), demonstrating a moderate to weak spatial dependence of SOC for the different soil layers which was controlled by both intrinsic and extrinsic factors.
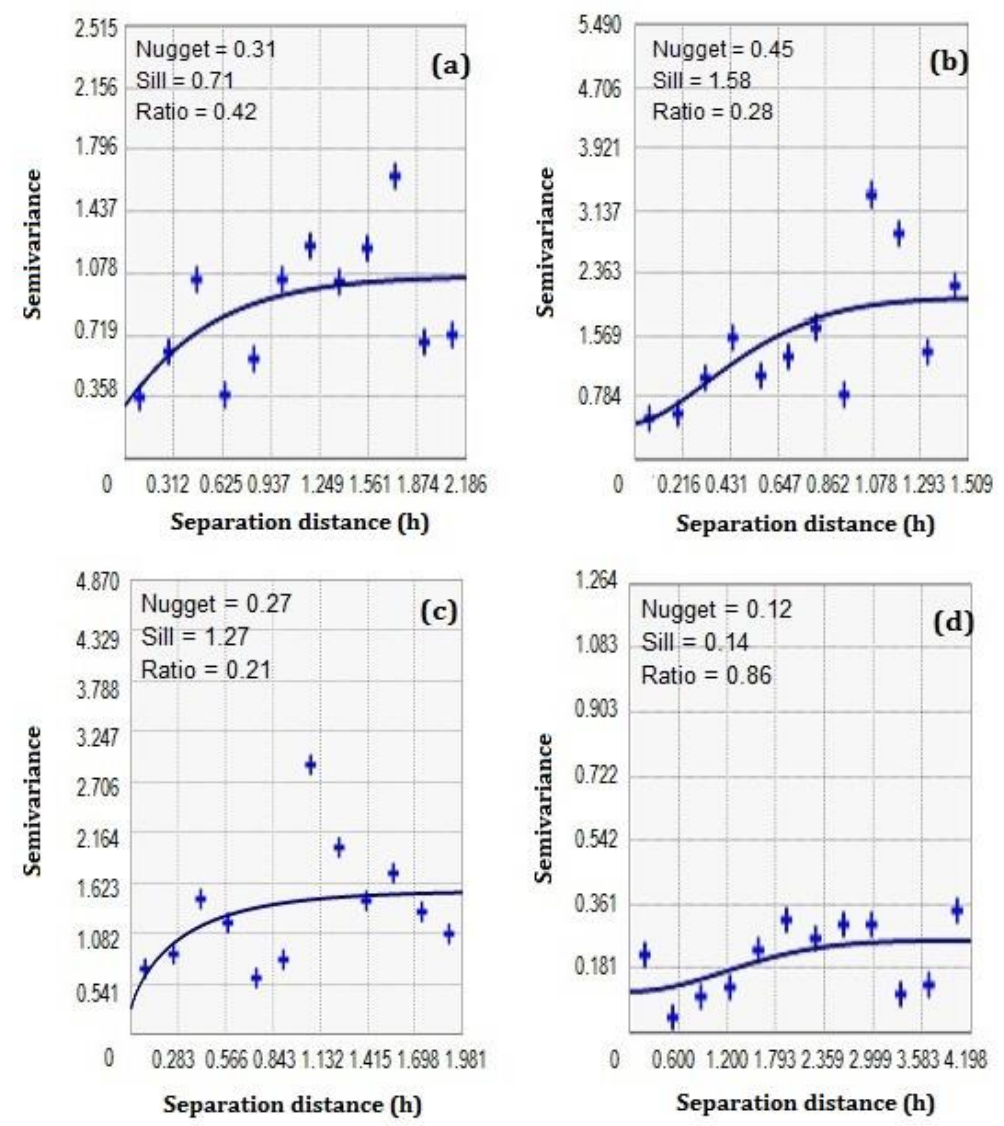

Figure 3. Experimental semivariograms and spatial models for SOC in the vertical direction at depths (a) 0-30 cm, (b) 30-60 cm, (c) $60-90 \mathrm{~cm}$, (d) $90-120 \mathrm{~cm}$ 
This was evidenced by local, intensive agricultural management, such as tillage and fertilization, widely used in the study area to improve the fruit and vegetables productivity (Sulieman et al., 2016). The maps of SOC spatial distribution generated depending on the measured SOC values and fitted variogram is shown in Figure 4. However the standard error maps of SOC spatial prediction is shown in Figure 5. According to Wang et al. (2009) and Fu et al. (2014), a strong spatial dependence of soil properties is attributed to soil intrinsic properties, such as soil parent materials, soil texture, topography and vegetation. Whereas, a weak spatial dependence of soil properties indicates that the spatial variability is mainly regulated by extrinsic variations, such as soil fertilization and cultivation practices, and moderate spatial dependence is controlled by both intrinsic and extrinsic factors (Kılıç et al., 2004; Wang et al., 2009). The exponential nature of the fitted semivariogram may indicate that SOC at the site had a gradual transition or that several patterns interfered. This variation in SOC levels can be attributed to the vertical illuviation of mineral and organic material from surface layers downward the soil profiles (Brodsky et al., 2013).
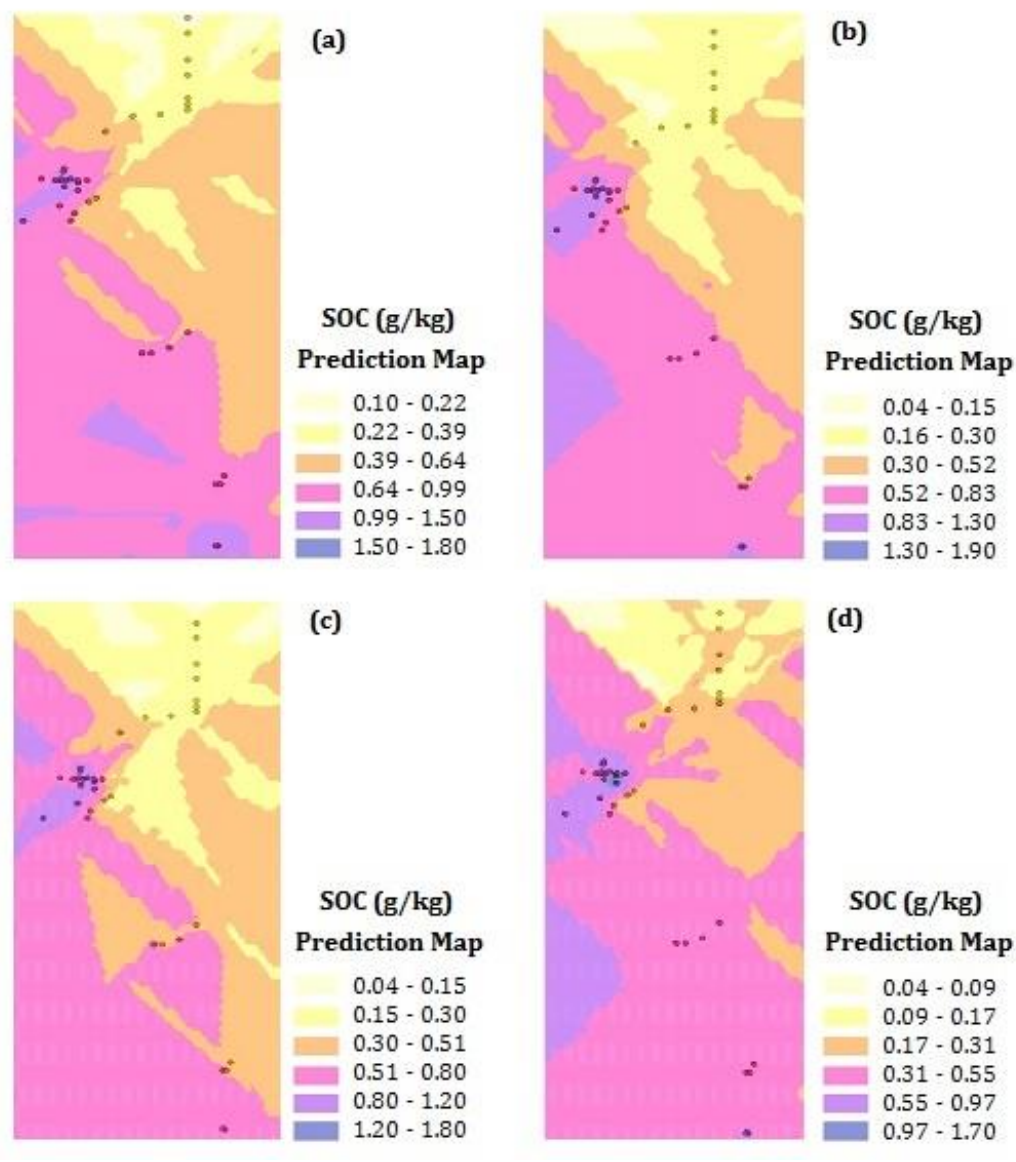

Figure 4. Maps of soil organic carbon spatial distribution, generated based on measured data and fitted variogram at soil depths (a) 0-30 cm, (b) 30-60 cm, (c) 60-90 cm, (d) $90-120 \mathrm{~cm}$

\section{Modeling validation}

The indices generated during the leave-out-one cross validation (LOCV) of OK model at four different depths are presented in Table 2. It was observed that goodness of fit between observed and predicted values was higher in surface soil layers than sublayers. The average standard error was 0.58 at depth $0-30 \mathrm{~cm}$ (RMSE $=$ $0.47), 0.57$ at depth 30-60 $\mathrm{cm}$ (RMSE = 0.43), 0.51 at depth 60-90 $\mathrm{cm}$ (RMSE =0.39), and 0.48 at depth 90-120 $\mathrm{cm}$ with the RMSE of 0.35 . The standardized RMSE was $0.83,0.79,0.80$, and 0.79 for the same depths grades, respectively. The RMSSE with a value closed to 1 indicating a perfect model (Tang et al., 2017). Overall, the RMSSE values in our study indicating that the model was correctly estimating the variability of SOC at the unsampled locations at the four different layers, and the best model was observed at the surface layer $(0-30$ $\mathrm{cm}$ ). Chabala et al. (2017) studied the spatial distribution of SOC at depth $0-20 \mathrm{~cm}$ in soils of a selected part of Zambia by using OK technique, they conclude that the model generated by OK was reliable in predict SOC and produce a RMSSE of 1.02. Figure 6 shows the predicted versus measured SOC, and the cross plot clearly indicated a weak to medium positive correlations. Further, there were no significant differences $(P>0.05)$ between the measured and predicted SOC in all soil layers when compared by the Sample t-test (Paired t-test). 
Table 2. Indices used for leave-out-one cross validation (LOCV) of ordinary kriging model for SOC prediction at different soil depths.

\begin{tabular}{llllll}
\hline Depth $(\mathrm{cm})$ & Mean & MS $^{\mathrm{a}}$ & ASE $^{\mathrm{b}}$ & RMSEc $^{c}$ & RMSSE $^{\mathrm{d}}$ \\
\hline $0-30$ & -0.006 & -0.015 & 0.58 & 0.47 & 0.83 \\
$30-60$ & -0.005 & -0.01 & 0.57 & 0.43 & 0.79 \\
$60-90$ & 0.003 & 0.00001 & 0.51 & 0.39 & 0.80 \\
$90-120$ & -0.003 & -0.001 & 0.48 & 0.35 & 0.79 \\
\hline
\end{tabular}

a Mean standardized; b average standard error; ${ }^{\mathrm{b}}$ root mean standard error; d root mean square error standardized.
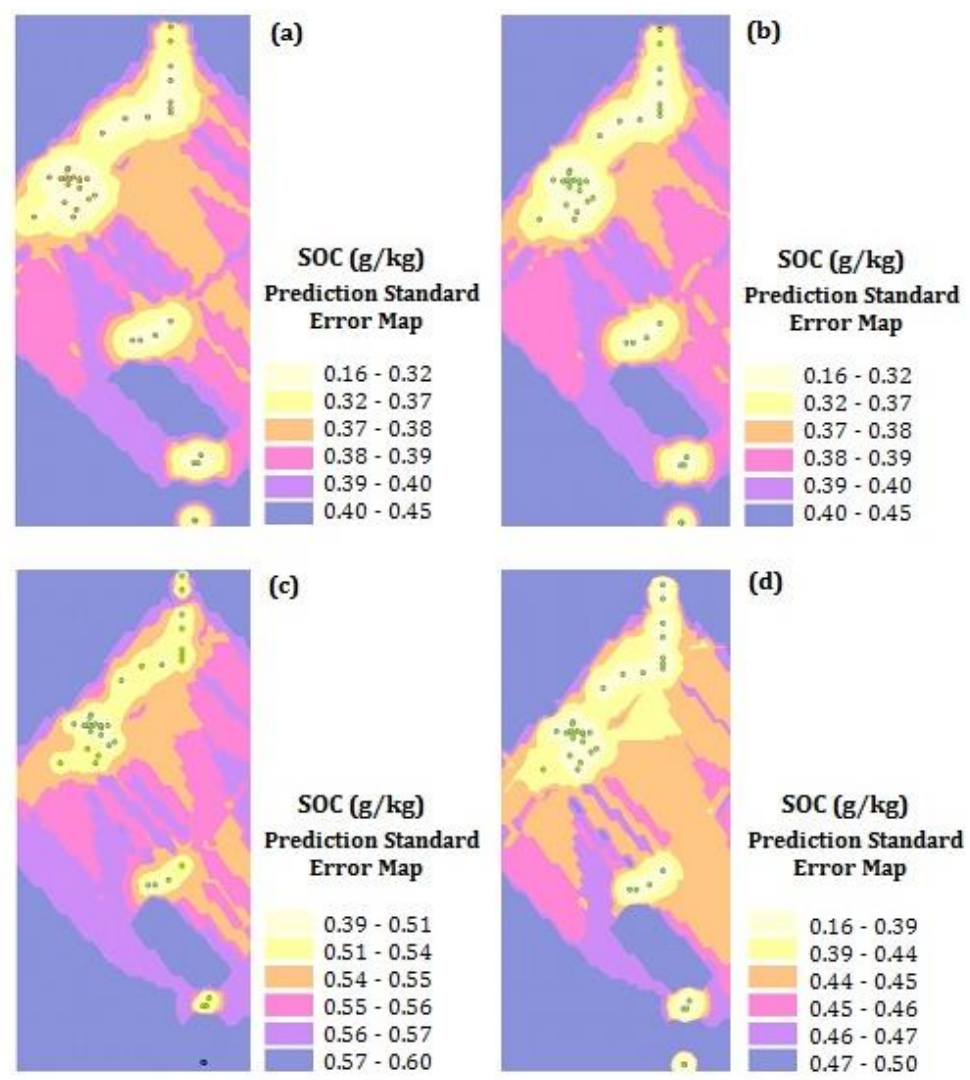

Figure 5. Standard error maps of SOC spatial prediction at soil depths

(a) 0-30 cm, (b) $30-60 \mathrm{~cm}$, (c) $60-90 \mathrm{~cm}$, (d) $90-120 \mathrm{~cm}$
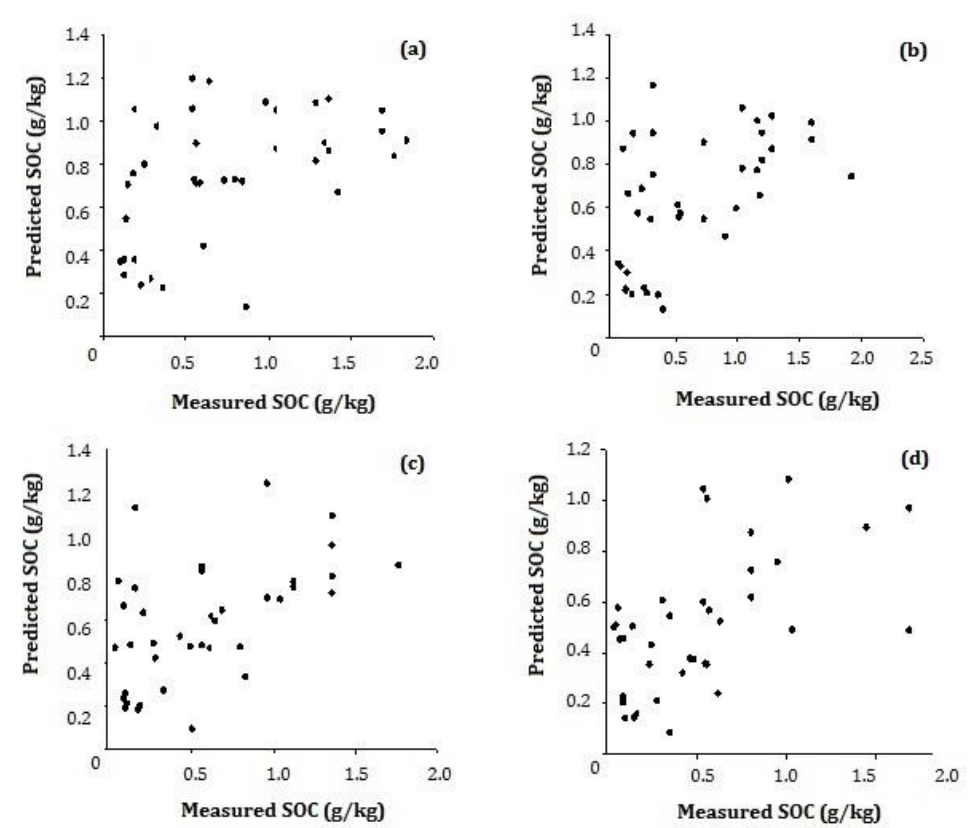

Figure 6. Cross-validation of OK interpolation for SOC at soil depths (a) $0-30 \mathrm{~cm} \mathrm{(b)} 30-60 \mathrm{~cm}$ (c) $60-90 \mathrm{~cm}$ (d) $90-120 \mathrm{~cm}$. 


\section{Conclusion}

In this study, OK was applied to study the spatial interpolation of SOC at 0-30 cm, 30-60 cm, $60-90 \mathrm{~cm}$ and 90-120 cm using the measured data from 152 samples in alluvium soils along Blue Nile and River Nile in Sudan. The results indicated that the short-range spatial dependence was moderate to weak with a nugget shifted from zero. Spherical model was selected to describe the spatial pattern of SOC in the study area. A moderate to weak spatial dependence of SOC was observed, indicating that SOC was controlled by both intrinsic factors (e.g. soil parent materials and soil texture) and extrinsic factors (e.g. application of fertilizers and tillage treatment).

\section{Acknowledgement}

The authors are gratefully thanks to the editors, and the two anonymous reviewers for their valuable comments and suggestions. Special thanks to Dr. Ian J. Slipper, Faculty of Engineering and Science, University of Greenwich, UK, for her linguistic review of this manuscript.

\section{References}

Acín-Carrera, M., José Marques, M., Carral, P., Álvarez, A.M., López, C., Martín-López, B., González, J.A., 2013. Impacts of land-use intensity on soil organic carbon content, soil structure and water-holding capacity. Soil Use and Management 29(4): 547-556.

Beguería, S., Angulo-Martínez, M., Gaspar, L., Navas, A., 2015. Detachment of soil organic carbon by rainfall splash: Experimental assessment on three agricultural soils of Spain. Geoderma 245-246: 21-30.

Behrens, T., Zhu, A.-X., Schmidt, K., Scholten, T., 2010. Multi-scale digital terrain analysis and feature selection for digital soil mapping. Geoderma 155(3-4): 175-185.

Bertalan, L., Tóth, C. A., Szabó, G., Nagy, G., Kuda, F., Szabo, S., 2016. Confirmation of a theory: reconstruction of an alluvial plain development in a flume experiment. Erdkunde 70(3): 271-285.

Bienes, R., Marques, M.J., Sastre, B., García-Díaz, A., Ruiz-Colmenero, M., 2016. Eleven years after shrub revegetation in semiarid eroded soils. Influence in soil properties. Geoderma 273: 106-114.

Bishop, T.F.A., McBratney, A.B., Laslett, G.M., 1999. Modelling soil attribute depth functions with equal-area quadratic smoothing splines. Geoderma 91(1): 27-45.

Bogunovic, I., Pereira, P., Brevik, E.C., 2017. Spatial distribution of soil chemical properties in an organic farm in Croatia. Science of the Total Environment 584-585: 535-545.

Bounouara, Z., Chevallier, T., Balesdent, J., Toucet, J., Sbih, M., Bernoux, M., Belaissaoui, N., Bouneb, O., Bensaid, R., 2017. Variation in soil carbon stocks with depth along a toposequence in a sub-humid climate in North Africa (Skikda, Algeria). Journal of Arid Environments 141: 25-33.

Cambardella, C.A., Moorman, T.B., Parkin, T.B., Karlen, D. L., Novak, J. M., Turco, R.F., Konopka, A.E., 1994. Field-scale variability of soil properties in central Iowa soils. Soil Science Society of America Journal 58(5): 1501-1511.

Camilli, B., Dell'Abate, M.T., Mocali, S., Fabiani, A., Dazzi, C., 2016. Evolution of organic carbon pools and microbial diversity in hyperarid anthropogenic soils. Journal of Arid Environments 124: 318-331.

Cotching, W.E., Oliver, G., Downie, M., Corkrey, R., Doyle, R. B., 2014. Land use and management influences on surface soil organic carbon in Tasmania. Soil Research 51(8): 615-630.

Chabala, L.M., Mulolwa, A., Lungu, O., 2017. Application of ordinary kriging in mapping soil organic carbon in Zambia. Pedosphere 27(2): 338-343.

Chahouki, Z., Chahouki, A.Z., Ahvazi, L.K., 2011. Comparing geostatistical approaches for mapping soil properties in Poshtkouh rangelands of Yazd Province, Iran. International Journal of Plant Research 24(1): 77-88.

Chen, C., Hu, K., Li, H., Yun, A., Li, B., 2015. Three-dimensional mapping of soil organic carbon by combining kriging method with profile depth function. PloS one 10(6): e0129038

Chen, C., Liu, W., Jiang, X., Wu, J., 2017. Effects of rubber-based agroforestry systems on soil aggregation and associated soil organic carbon: Implications for land use. Geoderma 299:13-24.

Dengiz, 0., 2010. Morphology, physico-chemical properties and classification of soils on terraces of the Tigris River in the south-east Anatolia region of Turkey. Tarim Bilimleri Dergisi 16(3): 205-212.

Dengiz, O., Sağlam, M., Türkmen, F., 2015. Effects of soil types and land use-land cover on soil organic carbon density at Madendere watershed. Eurasian Journal of Soil Science 4(2): 82-87.

Elfaki, J.T., Sulieman, M.M., Nour, A.M., Ali, M.E., 2015. Short-Term changes in inorganic nitrogen concentrations during storage at different temperatures of three different soils of the Nile River terraces, North of Sudan. Advances in Environmental Biology 9(24): 397-402.

Fang, X., Xue, Z., Li, B., An, S., 2012. Soil organic carbon distribution in relation to land use and its storage in a small watershed of the Loess Plateau, China. Catena 88(1): 6-13.

Fu, W., Jiang, P., Zhao, K., Zhou, G., Li, Y., Wu, J., Du, H., 2014. The carbon storage in moso bamboo plantation and its spatial variation in Anji County of southeastern China. Journal of Soils and Sediments 14(2): 320-329. 
García-Díaz, A., Allas, R.B., Gristina, L., Cerdà, A., Pereira, P., Novara, A., 2016. Carbon input threshold for soil carbon budget optimization in eroding vineyards. Geoderma 271: 144-149.

Gómez, J.A., Guzmán, M.G., Giráldez, J.V., Fereres, E., 2009. The influence of cover crops and tillage on water and sediment yield, and on nutrient, and organic matter losses in an olive orchard on a sandy loam soil. Soil and Tillage Research 106: 137-144.

Goovaerts, P., 1998. Geostatistical tools for characterizing the spatial variability of microbiological and physico-chemical soil properties. Biology and Fertility of Soils 27(4): 315-334.

Grunwald, S., 2009. Multi-criteria characterization of recent digital soil mapping and modeling approaches. Geoderma 152(3-4): 195-207.

Harrison, M.N., Jackson, J.K., 1958. Ecological classification of the vegetation of the Sudan. Ecological classification of the vegetation of the Sudan, Ministry of Agriculture and Forests, Khartoum, Sudan.

Hartemink, A.E., Minasny, B., 2014. Towards digital soil morphometrics. Geoderma 230-231: 305-317.

He, Y., Chen, D., Li, B.G., Huang, Y.F., Hu, K.L., Li, Y., Willett, I.R., 2009. Sequential indicator simulation and indicator kriging estimation of 3-dimensional soil textures. Australian Journal of Soil Research 47(6): 622-631.

Jin, K., Cornelis, W.M., Gabriels, D., Baert, M., Wu, H.J., Schiettecatte, W., Cai, D.X., De Neve, S., Jin, J.Y., Hartmann, R., Hofman, G., 2009. Residue cover and rainfall intensity effects on runoff soil organic carbon losses. Catena 78(1): 81-86.

Johannes, A., Matter, A., Schulin, R., Weisskopf, P., Baveye, P.C., Boivin, P., 2017. Optimal organic carbon values for soil structure quality of arable soils. Does clay content matter? Geoderma 302: 14-21.

Johnston, K., Ver Hoef, J. M., Krivoruchko, K., Lucas, N., 2001. Using ArcGIS geostatistical analyst (Vol. 380). ESRI Press, Redlands.

Keesstra, S., Nunes, J., Novara, A., Finger, D., Avelar, D., Kalantari, Z., Cerdà, A., 2018. The superior effect of nature based solutions in land management for enhancing ecosystem services. Science of the Total Environment 610-611: 9971009.

Kempen, B., Brus, D.J., Stoorvogel, J.J., 2011. Three-dimensional mapping of soil organic matter content using soil typespecific depth functions. Geoderma 162(1-2): 107-123.

Keshavarzi, A., Tuffour, H., Bagherzadeh, A., Duraisamy, V., 2018. Spatial and Fractal Characterization of Soil Properties across Soil Depth in an Agricultural Field, Northeast Iran. Eurasian Journal of Soil Science 7(2): 35-45.

Kılıç, K., Özgöz, E., Akbaș, F., 2004. Assessment of spatial variability in penetration resistance as related to some soil physical properties of two fluvents in Turkey. Soil and Tillage Research 76(1): 1-11.

Lado, M., Paz, A., Ben-Hur, M., 2004. Organic matter and aggregate-size interactions in saturated hydraulic conductivity. Soil Science Society of America Journal 68(1): 234-242.

Leuangthong, O., McLennan, J.A., Deutsch, C.V., 2004. Minimum acceptance criteria for geostatistical realizations. Natural Resources Research 13(3): 131-141.

Liu, Z.P., Shao, M.A., Wang, Y.Q., 2013. Spatial patterns of soil total nitrogen and soil total phosphorus across the entire Loess Plateau region of China. Geoderma 197-198: 67-78.

Martín, J.R., Álvaro-Fuentes, J., Gonzalo, J., Gil, C., Ramos-Miras, J.J., Corbí, J.G., Boluda, R., 2016. Assessment of the soil organic carbon stock in Spain. Geoderma 264: 117-125.

Ministry of Energy and Mines, 1981. Geological map of Sudan, scale: 1: 2,000,000, Geological and Mineral Resources Department, Sudan.

Mlih, R., Bol, R., Amelung, W., Brahim, N., 2016. Soil organic matter amendments in date palm groves of the Middle Eastern and North African region: a mini-review. Journal of Arid Land 8(1): 77-92.

Nasri, B., Fouché, O., Torri, D., 2015. Coupling published pedotransfer functions for the estimation of bulk density and saturated hydraulic conductivity in stony soils. Catena 131: 99-108.

Nelson, D.W., Sommers, L.E., 1982. Total carbon, organic carbon, and organic matter. In: Methods of Soil Analysis, Part 2, Chemical and Microbiological Properties, A.L. Page, R.H. Miller, D.R. Keeney (Eds.), 2nd Ed. Agronomy Monograph No. 9, ASA-SSSA, Madison, Wisconsin, USA. pp.539-573.

Peel, M. C., Finlayson, B. L., McMahon, T. A., 2007. Updated world map of the Köppen-Geiger climate classification. Hydrology and Earth System Sciences 11: 1633-1644.

Pereira, P., Brevik, E., Trevisani, S., 2018. Mapping the environment. Science of the Total Environment 610-611: 17-23.

Regalado, C.M., Ritter, A., 2006. Geostatistical tools for characterizing the spatial variability of soil water repellency parameters in a laurel forest watershed. Soil Science Society of America Journal 70(4): 1071-1081.

Reza, S.K., Sarkar, D., Baruah, U., Das, T.H., 2010. Evaluation and comparison of ordinary kriging and inverse distance weighting methods for prediction of spatial variability of some chemical parameters of Dhalai district, Tripura. Agropedology 20(1): 38-48.

Rodrigo Comino, J., Bogunovic, I., Mohajerani, H., Pereira, P., Cerdà, A., Ruiz-Sinoga, J., Ries, J., 2017. The impact of vineyard abandonment on soil properties and hydrological processes. Vadose Zone Journal 16(12).

Rosemary, F., Indraratne, S. P., Weerasooriya, R., Mishra, U., 2017. Exploring the spatial variability of soil properties in an Alfisol soil catena. Catena 150: 53-61.

Scharlemann, J.P., Tanner, E.V., Hiederer, R., Kapos, V., 2014. Global soil carbon: understanding and managing the largest terrestrial carbon pool. Carbon Management 5(1): 81-91. 
Schoeneberger, P.J., Wysocki, D.A., Benham, E.C., 2012. Field book for describing and sampling soils. National Soil Survey Center, Natural Resources Conservation Service, U.S. Department of Agriculture, Books Express Publishing, 298p.

Shiri, J., Keshavarzi, A., Kisi, O., Iturraran-Viveros, U., Bagherzadeh, A., Mousavi, S.R., Karimi, S., 2017. Modeling soil cation exchange capacity using soil parameters: assessing the heuristic models. Computer and Electronics in Agriculture 135: 242-251.

Smith, J.O., Smith, P., Wattenbach, M., Zaehle, S., Hiederer, R., Jones, R.J., Ewert, F., 2005. Projected changes in mineral soil carbon of European croplands and grasslands, 1990-2080. Global Change Biology 11(12): 2141-2152.

Soil Survey Staff, 2014. Keys to Soil Taxonomy, 12th ed. USDA-Natural Resources Conservation Service, Washington DC.

Steel, R., Torrie, G.D., 1980. Principles and Procedures of Statistics: A Biometrical Approach. McGrow-Hill: Sustainable Development. 663p.

Sulieman, M.M., Ibrahim, I.S., Elfaki, J., 2015. Evaluation of Land Suitability for Agriculture under Irrigation at Khartoum North, Sudan. International Journal of Scientific and Research Publications. 5(9).

Suliman, M.M., Ibrahim, I.S., Elfaki, J., 2015. Land suitability characterization for crop and fruit production of some river Nile Terraces, Khartoum North, Sudan. International Journal of Scientific and Research Publications 5(10).

Sulieman, M.M., Ibrahim, I.S., Elfaki, J.T., 2016. Genesis and classification of some soils of the River Nile terraces: a case study of Khartoum North, Sudan. Journal of Geoscience and Environment Protection 4: 1-16.

Sulieman, M., Saeed, I., Hassaballa, A., Rodrigo-Comino, J., 2018. Modeling cation exchange capacity in multi geochronological-derived alluvium soils: An approach based on soil depth intervals. Catena 167: 327-339.

Tang, X., Xia, M., Pérez-Cruzado, C., Guan, F., Fan, S., 2017. Spatial distribution of soil organic carbon stock in Moso bamboo forests in subtropical China. Scientific Reports 7: 42640.

Van der Kevie, W., 1976. Climatic zones in the Sudan. Soil Survey Department, Wad Medani, Sudan

Wang, Y., Zhang, X., Huang, C., 2009. Spatial variability of soil total nitrogen and soil total phosphorus under different land uses in a small watershed on the Loess Plateau, China. Geoderma 150(1-2): 141-149.

Whaiteman, A. J., 1971. The geology of the Sudan Republic. Oxford: Calorendon Perss.

Yang, Y., Zhu, J., Tong, X., Wang, D., 2009. The spatial pattern characteristics of soil nutrients at the field scale. In International Conference on Computer and Computing Technologies in Agriculture II., Volume 1. CCTA 2008. IFIP Advances in Information and Communication Technology, vol 293. Li, D., Zhao, C. (Eds.). Springer, Boston, MA., USA. pp. 125-134.

Zeraatpisheh, M., Ayoubi, S., Jafari, A., Finke, P., 2017. Comparing the efficiency of digital and conventional soil mapping to predict soil types in a semi-arid region in Iran. Geomorphology 285: 186-204. 